\title{
Modeling of Online Clinical System using Object- Oriented Data through UML
}

\author{
Suman Kumar Mishra, Ph.D \\ Institute of Management Sciences \\ University of Lucknow \\ Lucknow, Uttar Pradesh, India
}

\author{
Vansh Raj Upadhyay \\ Research Scholar, M.Tech. (CSE) \\ SITM, Lucknow (UPTU) \\ Lucknow, Uttar Pradesh, India
}

\begin{abstract}
In the last decade, the aggressive domain in clinical sector, paradigm is changing rapidly. Assorted new things can be seen in the clinical sector, because it is embracing new concept terminology and technology to enhance their business $\&$ to win the satisfaction of their patient. This paper discusses the role of Unified Modeling Language (UML) in the Object Oriented Database Management System (OODBMS) in clinical system. An attempt has been made to represent that the progress capabilities of object-oriented data facilitates a sharp and direct realization of the Event Model Database design was guided by two notion: (1) that there is an underlying shape to all clinical data and (2) that objects dwell within the database should serve interfaces to diversity of services. These services include decision corroborate information delivery and data exchange. The clinical domain explored was laboratory medicine. Conventional decisionsupport queries were run against the laboratory data information stored in the object-oriented database. Object oriented Data Modeling technique has been used to store the data repositories.
\end{abstract}

\section{Keywords}

UML Diagrams, Object - Oriented Data and Clinical System

\section{INTRODUCTION}

The basic objective of the clinical database system is to share information and improve service quality. Clinical database system is too heterogeneous and structurally complex. In addition, the desire to make clinical information conform to "preset categories" appears to be frustrated by the fact that clinicians do not hesitate to use the powers of natural language to express niceties of meaning. Nevertheless, it is considered $[3,7,8,2,9,10,11,12]$ that encoded representations of medical data are required for the purposes of decision support and information exchange across heterogeneous systems. The requirement for a shared encoding system becomes obvious in the case of data sharing between branches of hospital services belonging to different countries, where the original documents may have been written in different natural languages [3].

The Event Definition (ED) Model defining conceptual basis for storing patient information. It has previously been used as the basis for the database capture of echocardiography reports [13], for mapping between vocabularies of two hospital information systems [14] and for automated mapping between the ILIAD expert system's dictionary and the UMLS Meta thesaurus [15]. A full account of the model, along with illustrative examples and notes on its evolution may be found in the recent paper by Huff et al. [1]. The following ideas constitute the ED Model, as it stands today:
- The clinical information world is composed of objects which have relationships with each other.

- Objects with common characteristics can be categorized by other objects and by object types which denote those common characteristics.

- Real-world objects are actual instances of object types in the clinical world such as a particular patient or a particular clinician.

- An event is said to have occurred when two or more real-world objects interact with each other.

- Every event instance is the result of instantiating an Event Template (ET). ETs have attributes and belong to a hierarchy such that ETs lower in the hierarchy inherit the attributes of those above them.

The two principle event types are patient-related and nonpatient-related events (such as hospital administration orders). This work does not deal with events of the second type; henceforth the term event will refer only to patient-related events.

The following are concrete examples of patient-related events:

1. The performance of an appendicectomy.

2. A blood pressure measurement.

3. An observation made by a radiologist in a chest $x$-ray.

The basic model defines the set of attributes which store the data related to clinical database system. Every attribute has a set of implicit attributes: these are Value, Relational Operator, Value Format, Units. Etc. All incidents have the following common attribute:

- Patient entity.

- The time of incident.

- The time at which the event was stored in the system.

- The clinician who observed or recorded that event.

- An entity which serves to differentiate it from every other event instance.

An important implied property of the ED Model is that the domains are atomic in nature.

\section{COMPARISON BETWEEN CLINICAL OODBMS AND RDBMS:}

Today's object-oriented database management system (OODBMS) support complex queries and handle the large amount of the data. In given table below comparison has been 
given between Relational Data Model and Object Oriented Data model (ODM)

Table 1. Comparison between clinical OODBMS and RDBMS

\begin{tabular}{|l|l|l|l|}
\hline S. No. & Challenges & Clinical RDBMS & Clinical OODBMS \\
\hline 1. & Length of strings & Fixed length & Create new data type \\
\hline 2. & Version & Do not support lower version & Support old and new version \\
\hline 3. & Transaction & $\begin{array}{l}\text { Support recent state possible } \\
\text { transaction }\end{array}$ & $\begin{array}{l}\text { Support Integrated transaction with concurrency and } \\
\text { recovery. }\end{array}$ \\
\hline 4. & Schema & $\begin{array}{l}\text { Do not support dynamic } \\
\text { mechanism }\end{array}$ & Support dynamic mechanism \\
\hline 5. & Complexity & $\begin{array}{l}\text { Support classical database } \\
\text { structure }\end{array}$ & Support dynamic and object oriented database \\
\hline
\end{tabular}

\section{CASE STUDY: CLINICAL INFORMATION SYSTEM}

The Clinic has several specialized departments like Orthopedics, OPD, Dental, Gynecology, etc. OPD is diverse independent department. A doctor is only correlated with one specialized department at a time though he/she can be a constituent of the OPD (Outside Patients Department) department. Each doctor has a visiting time and day in a week.

At online clinical system the patient records will be display on the basis of the patient_id using object oriented database.

In routine a patient can consult the doctors either by directly selecting a doctor or by getting admitted to the Clinic and then doctor talks with the patients.

A doctor can prescribe tests for the patient to perform. The patient consult the lab to get done the tests prescribed by his/her doctor. The multi-dimensional reports will be given to the patient. The online payments pertaining to the tests will take place at the payment gateways. Referring the reports, the doctor prescribes the patient medicines or further tests or is asked to get admitted.
A patient will be admitted into a ward of a specialized department (if available) as per the doctor's prescription. The numbers of wards are limited and if there is no vacant ward the admission of the patient will be rescheduled.

As per the prescription of the doctor the patient is operated on a specified date and time as decided by the doctor who will do the operation.

Patient may get discharge on the bases of a doctor recommendation and upon the complete payment of all due charges at the payment gateways. If patient will be given full payment then the payment gateways generates a discharges report for the patient.

Clinical information system explains through following UML diagrams:-

\subsection{Use Case Diagram:}

In figure 1, the use Case Diagram of Clinical Information System, four actors Patient, Doctors, Nurse and Staff. The diagram involves a sequence of messages between the use cases and the actors. 


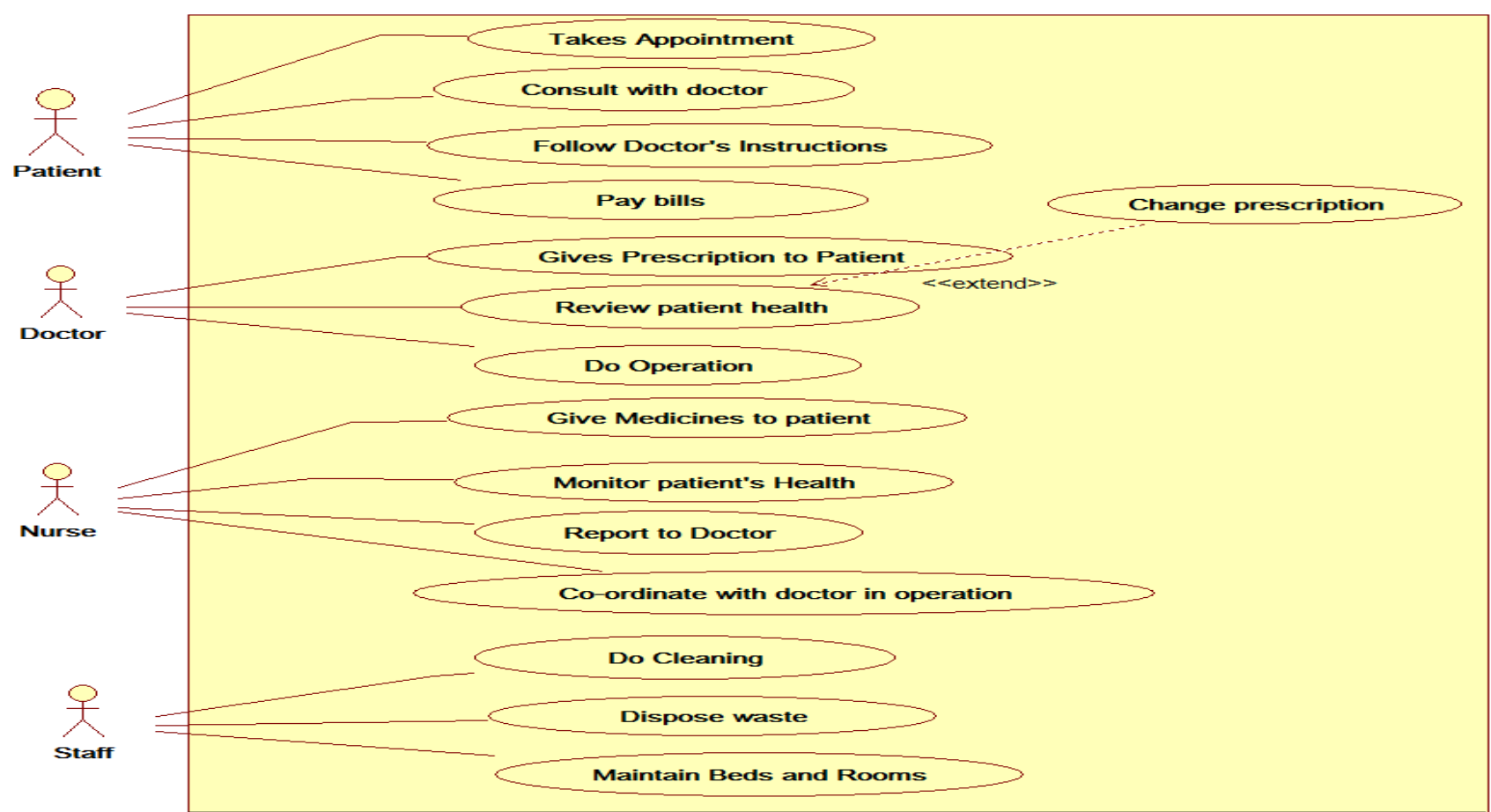

Figure1: Use Case Diagram Online Clinical System

\subsection{Class Diagram:}

In figure: 2, class diagram involves the online registration, patients, doctors, ward, test $\&$ reports, and medicine. In the clinical information system, the patient first registers in clinical information system and appointment and required document list will be generated by online clinical system using object oriented databases, after that patient comes at given schedule time with required documents and consults doctor and doctor checks all documents and reports (like pathology, x-ray, ultrasound etc which is necessary) and maintains all details about test and their medicine for future investigation. The details of the patient can be viewed online by entering the patient_id.

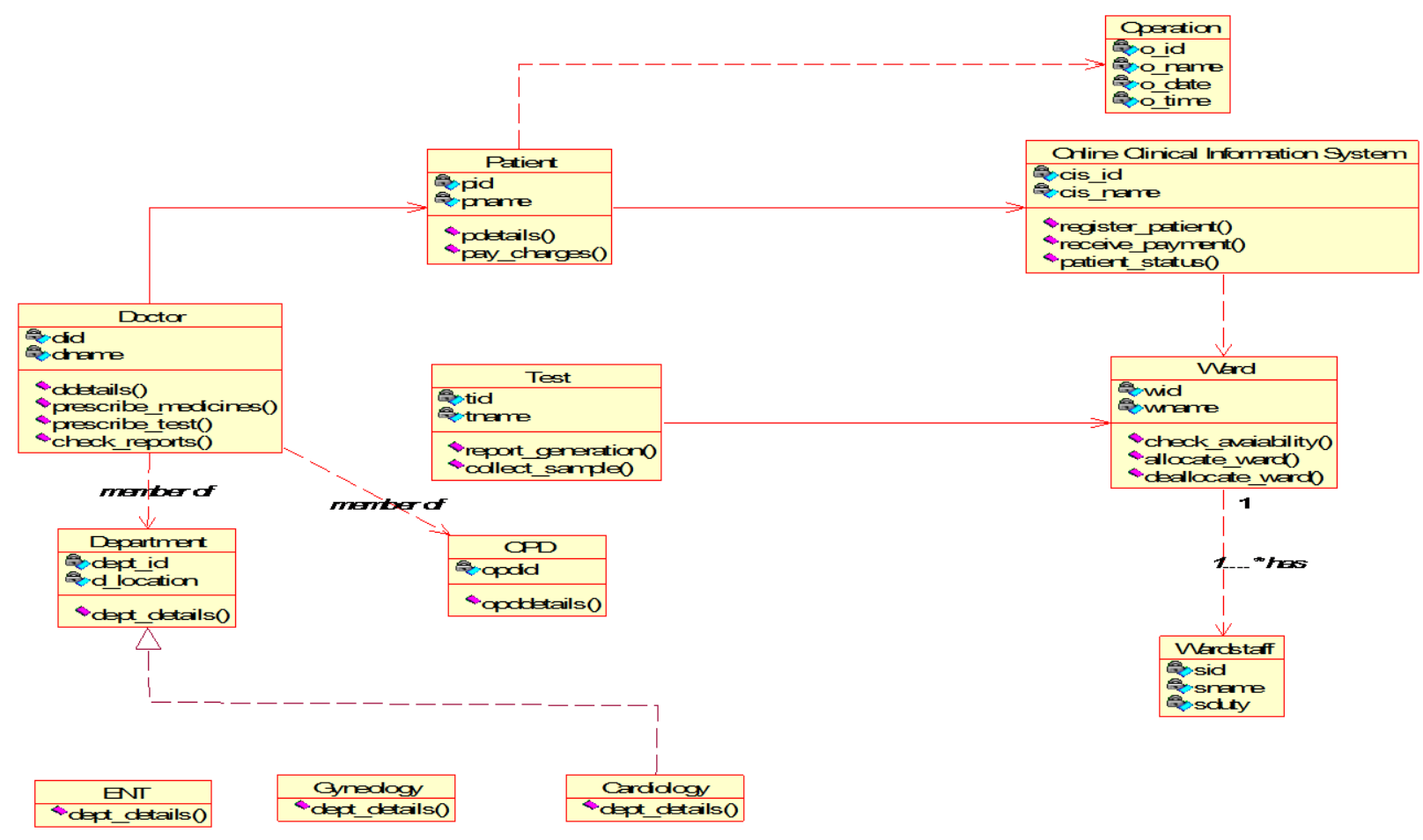

Figure 2: Class Diagram for Clinical Information System 


\subsection{Sequence Diagram}

Figure 3 presents the sequence diagram of clinical information system. As shown above class diagram shows that how Doctor handle smoothly the Clinical Information System (like details of patient, test, medicine, and all checkups reports). In the Clinical Information System, the patient first registers in clinical information system and appointment will be generated by online system using object oriented database, after that patient comes at given schedule time and consult to doctor and doctor prescribe medicine and test. After that completion of the treatment a patient may get discharged on an advice of a doctor and upon the complete payment of all due charges at the payment gateways. On payment of full dues the payment gateways generates a discharges report for the patient.

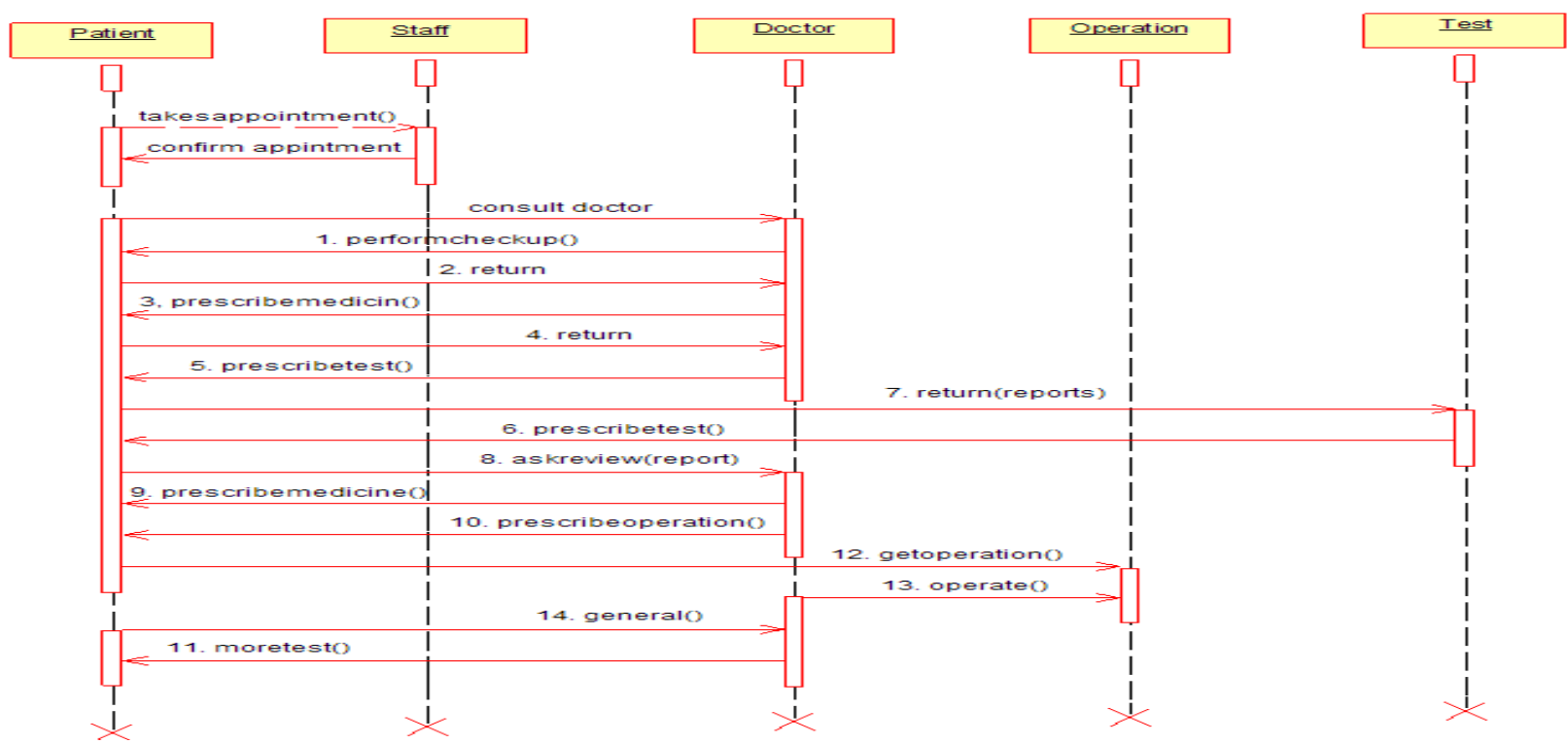

Figure 3: Sequence Diagram for Patient Registration, Consult Doctor and Operation

\subsection{State Diagram}

Figure 4 presents the state diagram of Clinical Information System, which shows track of Clinical Information System. Firstly, patient will register through online and at the time of registration he/she will select a doctor and takes appointment from online bases clinical information system. A doctor can prescribe tests and medicines for the patient. The online payments pertaining to the tests will happen at the payment gateways..

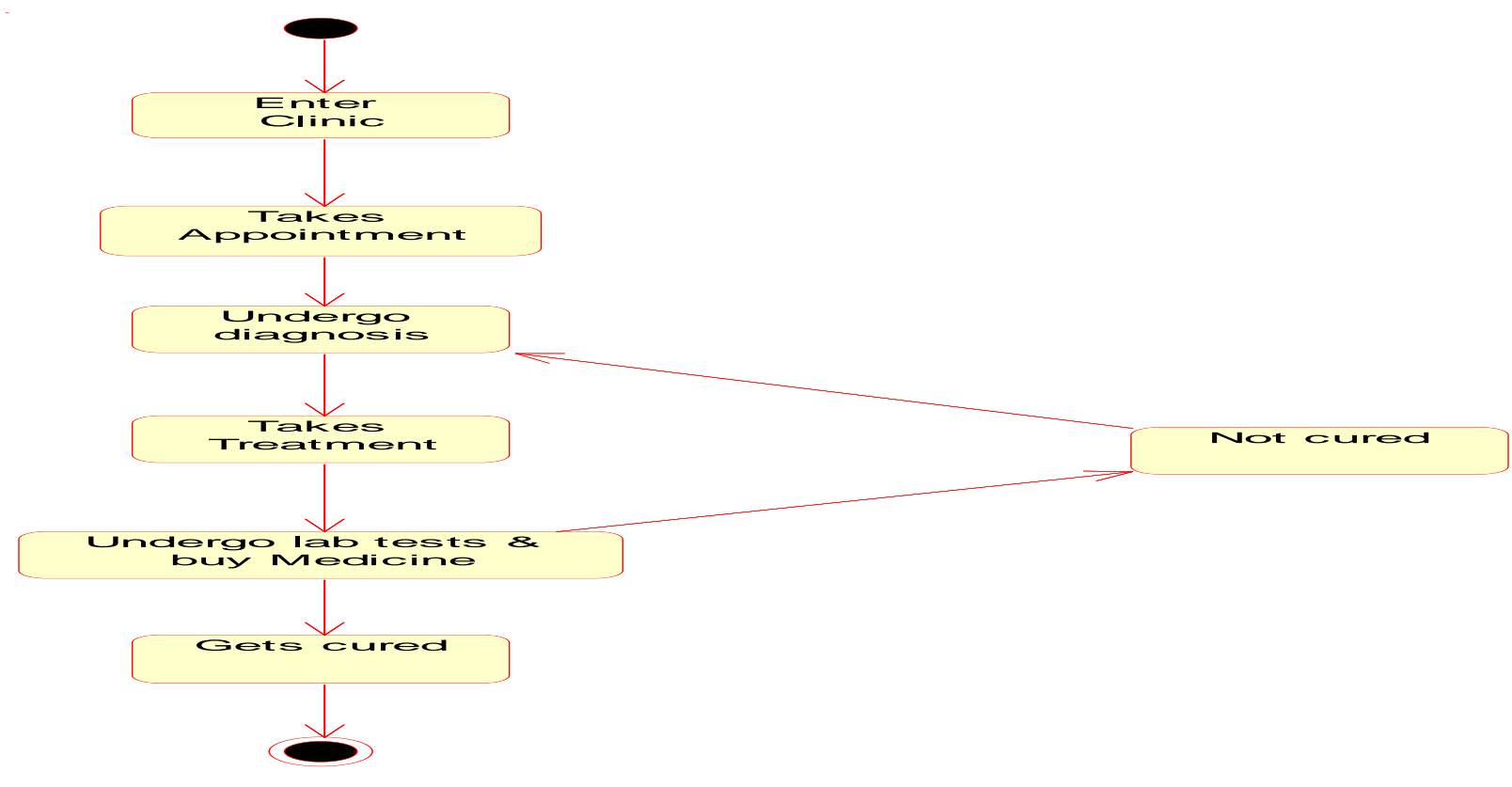

Figure 4: State diagram for Doctor of Online Clinical System 


\subsection{Activity Diagram:}

Figure 5 presents the activity diagram of Clinical Information System. Activity diagram shows that patient will first enter in clinic and go to online clinical system for registration. The online clinical system identifies whither it is a new patient or existing patient based on the patient_id. If it is a new patient then online clinical system asks the patient for appointment from doctor and checks doctor status, if doctor is available then confirms appointment and patient consults the doctor. If doctor is not available then gives appointment date and time to patient. If it is an existing patient then checks details about patient (like treatment information, test operations and reports) and checks status about consulting doctor. If available, then confirms appointment for remaining treatment, otherwise, gives appointment date and time for remaining treatment.

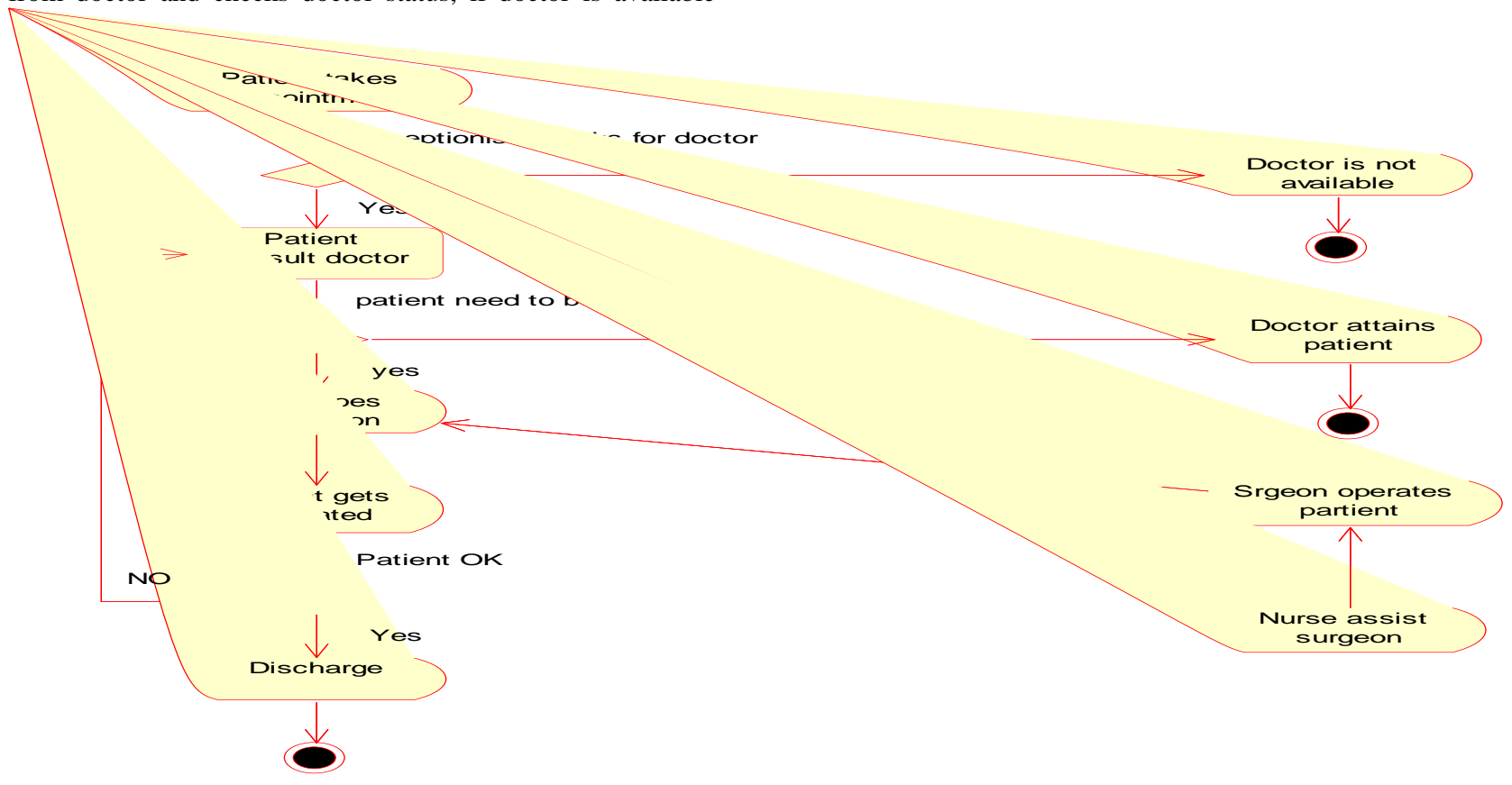

Figure 5: Activity diagram for Clinical Information System

\subsection{Collaboration Diagram}

Figure 6 presents the collaboration diagram of Clinical Information System. It depicts the formalized relationship of Online Clinical Database System and the messages sent/received. Formalized relationship consists of objects and links. The aim of collaboration diagram is similar to sequence diagram. But the main aim of collaboration diagram is to ideate the constitution of objects and their interplay.

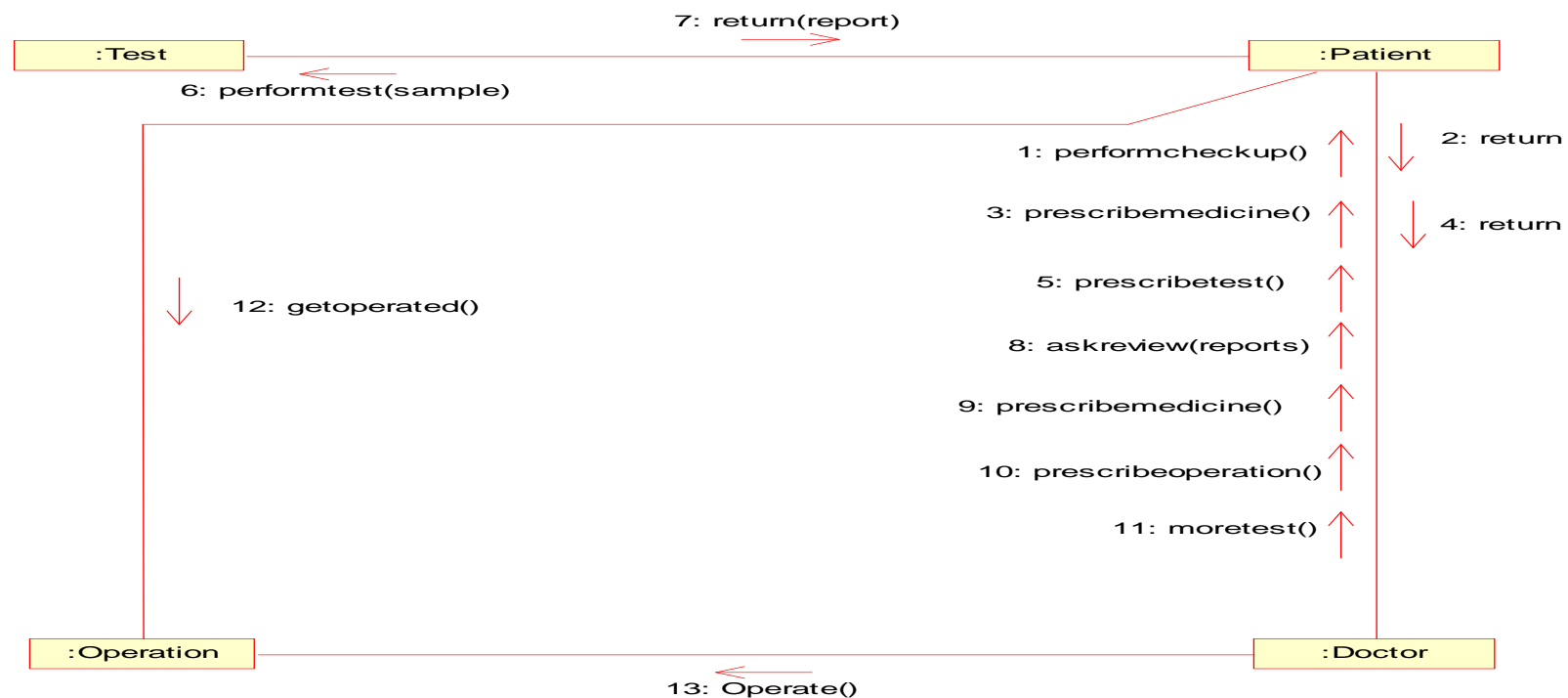

Figure 6: Collaboration diagram for test +Operation of clinical System 


\section{EXPERIMENTAL RESULTS:}

We have implemented the online clinical system using object oriented concepts and UML. The system used is an Intel core i3- 3110 M Processor with 4 GB DDR3 RAM, running Microsoft Windows 2008 and Rational Rose Software. The system was implemented using Versant and Active X Data Model (ADO). Experimental results show that two different queries running at the same time and queries screenshot given below in figure 7 :

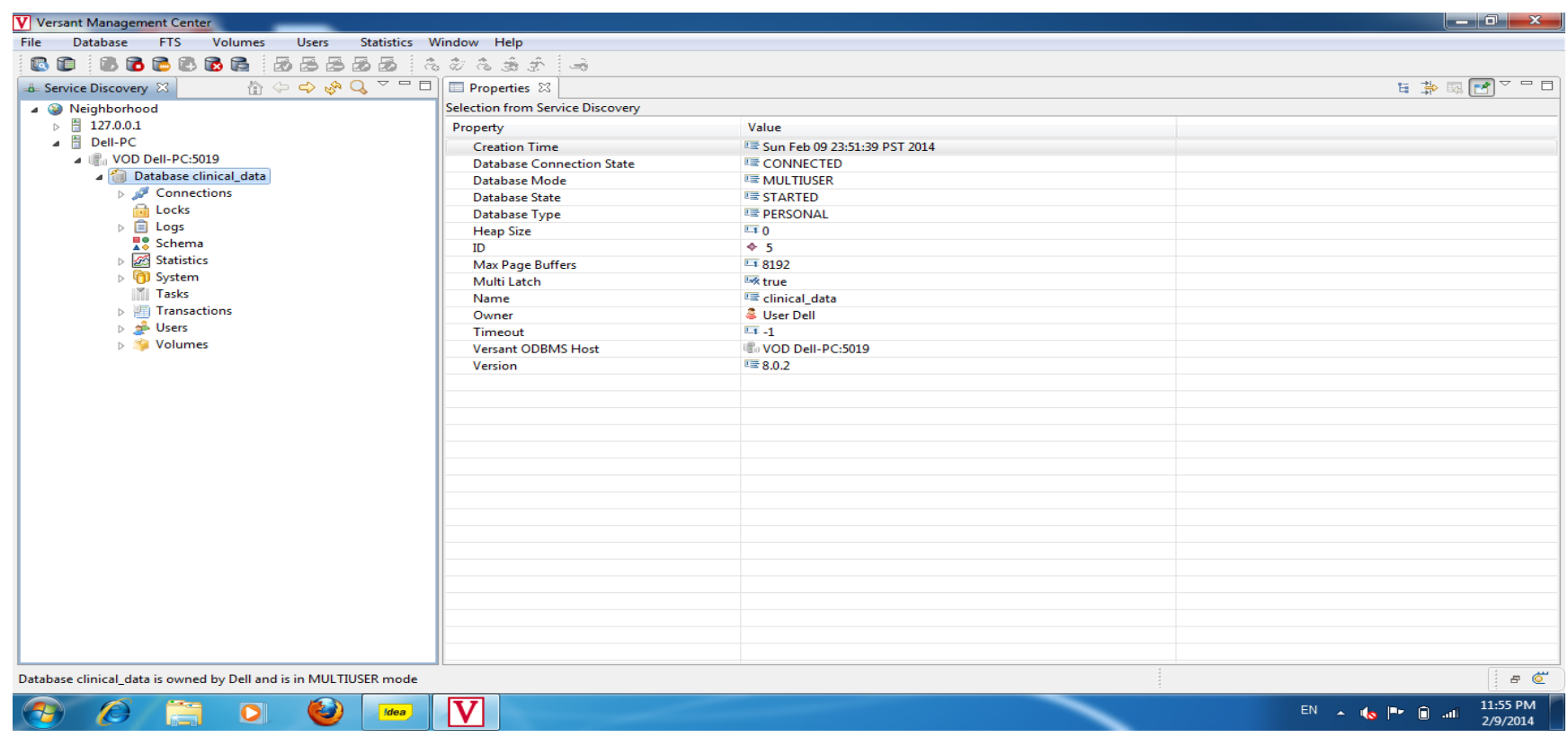

Figure 7: Queries of Schreenshot

\section{IMPLEMENTATION}

Task of Clinical Information system through Object Oriented Software (Versant) Solutions is shown in Figure 8. The result is shown in term of OPD, patient_id, payment mode, date and time with patient details. The proposed online clinical system is implemented and the experimental results are shown below figure 8 :

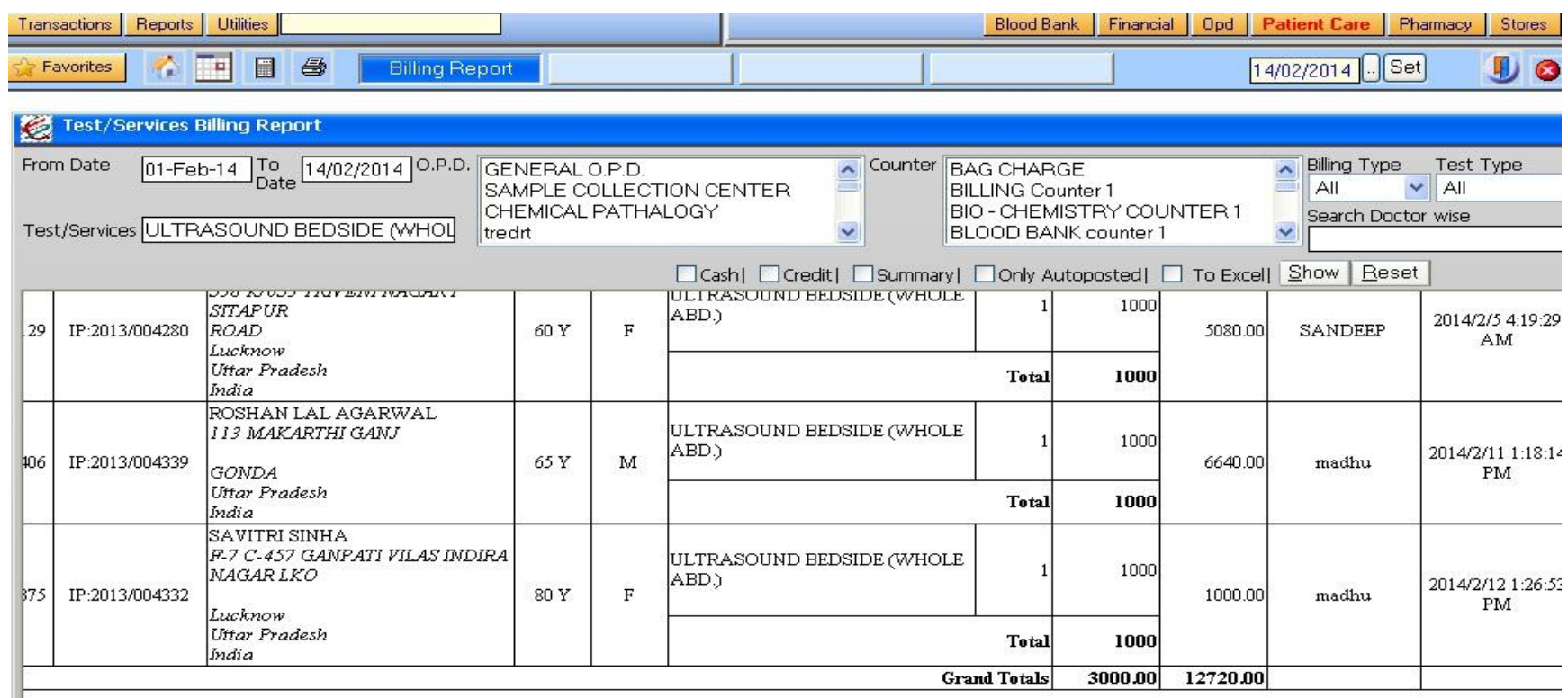




\section{CONCLUSION \& FUTURE SCOPE}

From the analysis and discussion, we observed that ObjectOriented Database Management Systems (OODBMS) were limited in the past because of a lack of standardization. But today we have standard OODBMS such as Objectivity and versant object-oriented database software through which it is easy to deal with the complex and huge amount of clinical data's. In this paper we have shown how the traditional clinical system is converted into innovative clinical system. The present work can be easily extended by designing of the multi-dimensional cubes for the many major fields shown in the sample database and one can easily extract the information in more efficient manner about the patient and their id (of patient) along with the date of treatment, test operations and reports renewal. The same work can also be extended for the storing of huge amount patient information like medicine, reports (x-ray, ultrasound, etc) in format of multimedia information.

\section{ACKNOWLEDGEMENTS}

I especially extend my sincere and grateful thanks to Prof. Harsh Dev, Dean (Academic), PSIT, Kanpur, and Uttar Pradesh, India.

I would like to first thank Mr. Babu Lal (HOD of CSE, SITM Lucknow) for giving me the opportunity to join him in his research, and for leading me to this research paper. Also, for all of his help and guidance throughout the process, and for all of the time spent discussing and reviewing my work. His detailed comments and insight were invaluable.

In addition, a word of mention also goes to all our colleagues who were a constant source of help and suggestions. Without their help this report would not have been in its present form.

\section{REFERENCES}

[1] Huff, S. M., Rocha, R. A., Bray, B. E., Warner, H. R. \& Haug, P. J. An event model of medical information representation. Journal of the American Medical Informatics Association 2(2),116-128 Mar/Apr (1995).

[2] Evans, D. A., Cimino, J. J., Hersh, W. R., Huff, S. M. \& Bell, D. S. Towards a medicalconcept representation language. Journal of the American Medical Informatics Association 1(3), 207-216 May / Jun (1994).

[3] Rossi-Mori, A., Galeazzi, E., Gangemi, A., Pisanelli, D. M. \& Thornton, A. M. The transfer of medical concepts in a multilingual environment. In Proceedings of the Workshop: Issues in Transfer of Medical Data, Information and Knowledge, 1-14, (1990).

[4] Hurson A. R. And Pakzad H. Object Oriented Database Management System: Evoluation and Performance Issues, IEEE Publication, 1993.
[5] Kim Wom, Research Directions in Object - Orieneted Database System, 1990, ACM Publication

[6] Rumbaugh, James, Ivar Jacobson, and Grady Booch (2005) The Unified Modeling Language Reference Manual, 2nd ed. Addison-Wesley, Boston.

[7] McDonald, C. J. Standards for the electronic transfer of clinical data: Progress, promises, and the conductor's wand. In Proceedings of the Fourteenth Symposium on Computer Applications in Medical Care, (Miller, R. A., ed), 9-14 (1EE Computer Press, Los Angeles, 1990).

[8] Rector, A. L., Nowlan, W. A. \& Kay, S. Foundations for an electronic medical record. Medical Informatics 30(3), 179-186 (1991).

[9] Board of Directors of the American Medical Informatics Association. Standards for medical identifiers, codes, and messages needed to create an efficient computer-stored medical record. Journal of the American Medical Informatics Association (1994).

[10] Kuperman, G., Gardner, R. \& Pryor, T. A. HELP: A Dynamic Hospital Information System. Springer-Verlag, New York, (1991).

[11] Nelson, B. D., Gardner, R. M., Hedrick, G. \& Gould, P. Computerized decision support for concurrent utilization review using the HELP system. Journal of the American Medical Informatics Association 1, 339-352 (1994).

[12] Thomsen, G. E., Pope, D. \& East, T. E. Clinical performance of a rule based decision support system for mechanical ventilation of ARDS patients. In Proceedings of the Seventeenth Symposium on Computer Applications in Medical Care, (Safran, C., ed), 339-343 (McGrawHill, New York, 1993).

[13] Canfield, K., Bray, B., Huff, S. \& Warner, H. Database capture of natural language echocardiology reports. In Proceedings of the Thirteenth Symposium on Computer Applications in Medical Care, (III, L. K., ed), 559-563 (IEE Computer Press, Los Angeles, 1989).

[14] Fu, L. S., Bouhaddou, 0., Huff, S. M., Sorenson, D. K. \& Warner, H. R. Toward a public domain UMLS patient database. In Proceedings of the Fourteenth Symposium on Computer Applications in Medical Care, (Miller, R. A., ed), 170-174 (IEE Computer Press, Los Alamitas,CA, 1990).

[15] Rocha, R. A., Rocha, B. H. S. C. \& Huff, S. M. Automated translation between medical vocabularies using a frame-based interlingua. In Proceedings of the Seventeenth Symposium on Computer Applications in Medical Care, (Safran, C., ed), 690-694 (McGraw-Hill, New York, 1993). 